\title{
PATROCINIO O MECENAZGO: UNA ESTRATEGIA DE LA EMPRESA EN EL DESARROLLO CULTURAL
}

\author{
Juan Francisco Aráez Fernández \\ Universidad Europea. Dep. Comunicación audiovisual y publicidad, Madrid, España
}

\section{Resumen:}

La cultura como principio digno de tutela, protección y fomento por parte de los Poderes Públicos es el signo determinante de la mayoría de los países desarrollados hasta el punto de ser recogida en los textos constitucionales -sobre todo tras la II Guerra Mundial- para garantizar dicho estatus. Puesto que de dicho elemento integrador e identificador deben disfrutar todos los ciudadanos, se hace necesaria en esta labor de promoción de la misma la intervención de todos los miembros de la sociedad en la que se proyecta, superando esquemas y posiciones ideológicas. Así la empresa a través de fórmulas como el mecenazgo y patrocinio cultural, ha conseguido superar como exclusivos los objetivos del puro beneficio mercantil y revirtiendo estos en la misma sociedad de la que forma parte, mejorando su imagen.

A través de la experiencia se ha puesto de manifiesto que la fórmula de sistemas mixtos -Estado y particulares, en este caso empresas- en la participación del fomento de la cultura a través de mecanismos como el patrocinio y el mecenazgo, que a su vez se convierten en elementos de comunicación de empresa, favorecen el desarrollo de la cultura implicando a todos los miembros del grupo humano, permitiendo la identificación de éstos en el resultado.

Palabras clave: Cultura - Patrocinio- Mecenazgo - Empresa - Promoción

\section{REFLEXIONES SOBRE ESTRATEGIA EMPRESARIAL}

El hecho diferenciador que separa la sociedad humana de la animal es la cultura. Tylor, en su ya clásica definición, considera que la cultura es:

"un complejo que comprende conocimientos creencias, arte, moral, leyes, usos y otras capacidades y usanzas adquiridas por el hombre en cuanto miembro de una sociedad."

La cultura es, por tanto, un acto distintivo del hombre; es, en definitiva, el hecho peculiar que distingue a una sociedad.

Sin embargo, no es nuestro objetivo pretender analizar un concepto tan amplio y a la vez tan complejo como es el fenómeno cultural sino tratar de determinar a quién corresponde su tutela y desarrollo y cuáles son los recursos y mecanismos empleados en su promoción. 
De acuerdo con ello, comenzaremos diciendo que resulta evidente la responsabilidad del Estado en el desarrollo cultural de un país puesto que parece ser que es a éste a quien corresponde el establecimiento de una política cultural y cualquier referencia a la misma, comúnmente, ha sido asociada con los poderes públicos.

Así, por ejemplo, Guy de Brebisson nos dirá que en países como Francia, Suiza y Suecia se pensaba hasta hace unos años que la cultura por su carácter de interés público debía ser una función de responsabilidad exclusivamente estatal.

En efecto, será el interés público la base fundamental para atribuir al Estado la responsabilidad de satisfacer las necesidades culturales, prestando el obligado servicio público.

Prestación que nuestra Carta Magna contempla en su Preámbulo al señalar que:

La Nación española, deseando establecer la justicia, la libertad y la seguridad y promover el bien de cuantos la integran, en uso de su soberanía, proclama su voluntad de:

... Promover el progreso de la cultura y de la economía para asegurar a todos una digna calidad de vida.

Y en su Título Preliminar el artículo 9.2. establece que:

Corresponde a los poderes públicos promover las condiciones... y facilitar la participación de todos los ciudadanos en la vida política, económica, cultural y social.

Como desarrollo a tales principios generales, el Título primero (de los derechos y deberes fundamentales) dedica el Capítulo tercero a los principios rectores de la política social y económica. Pues bien, el artículo 44.1. (Acceso a la cultura), dispone que:

Los poderes públicos promoverán y tutelarán el acceso a la cultura, a la que todos tienen derecho.

Y el artículo 46 dedica su redacción a la conservación del patrimonio artístico, estableciendo que:

los poderes públicos garantizarán la conservación y promoverán el enriquecimiento del patrimonio histórico, cultural y artístico de los pueblos de España...

Por todo ello, el Título octavo referido a la organización territorial del Estado, en su Capítulo tercero (de la Comunidades Autónomas), el artículo 149 señala las competencias exclusivas del Estado y en su apartado 2 señala el servicio del Estado a la Cultura, cuya redacción dice que:

Sin perjuicio de las competencias que podrán asumir las Comunidades Autónomas, el Estado considerará el servicio dela cultura como deber y atribución esencial y facilitará la comunicación cultural entre las Comunidades Autónomas, de acuerdo con ellas. 
De acuerdo con lo que establece el texto constitucional, corresponde, por tanto, a los poderes públicos (Ministerio de Cultura, las Comunidades Autónomas, Diputaciones y

Ayuntamientos) satisfacer las necesidades culturales de la sociedad civil por medio de los presupuestos públicos.

Ahora bien, ¿la sola intervención del Estado es suficiente para dar respuesta a la demanda cultural?

Entendemos que no, puesto que el principal problema que plantea cualquier política cultural lo constituye su financiación.

En efecto, el problema apuntado en el párrafo anterior existe y el Estado, como nos recuerda Francesca Minguella,

... no puede hacer frente a necesidades sociales nuevas o crecientes debido al elevado déficit del sector público, incluso en coyunturas económicas favorable.

De ahí que, cuando el esfuerzo realizado por el Estado resulte insuficiente para satisfacer las demandas culturales de la sociedad, será la iniciativa privada, en definitiva, la empresa quien asuma la responsabilidad.

Ello no significa que la empresa, en materia cultural, asuma el papel atribuido al Estado sino que su función consiste en adoptar una posición complementaria a la encomendada a los poderes públicos.

Las posibilidades, por tanto, entre lo público y lo privado, como señalara el otrora Subdirector General de Estudios y Asistencia Técnica del Ministerio de Cultura, Ángel Luis Martín Serrano,

... son muy extensas, abarcando desde las subvenciones al patrocinio de actividades, la cofinanciación de proyectos, la cooperación técnica y financiera y otras. Esta colaboración adquiere una mayor importancia cuando el Estado se reconoce como incapaz de atender a la gran demanda cultural existente, por lo que es el propio mundo cultural el que de alguna forma debe autogenerarse.

Naturalmente, esta autogeneración se traduce en la adopción de un modelo mixto (Estado-iniciativa privada) por medio del cual la empresa asume su compromiso con la sociedad cubriendo aquellas demandas culturales donde el Estado no puede llegar y éste, a la vez que controla, reconoce ese compromiso mediante la concesión de determinados beneficios fiscales a aquellas empresas que ayudan económicamente en determinadas actividades de interés cultural general.

Consecuentemente, en esta forma de privatización de las funciones públicas por parte de la empresa el mecenazgo o patrocinio cultural constituyen las estrategias adecuadas las cuales se suelen canalizar en nuestro país a través de las fundaciones. 
Parés i Maicas, autor muy conocido en estos ámbitos, no duda en afirmar al respecto que:

Resulta indispensable la existencia de una política cultural privada, fundamentalmente a través del mecenazgo y de las fundaciones. Con independencia del papel que en este cometido tiene la sociedad civil, debe resaltarse la función capital que asume la empresa mercantil como célula básica de aquél, es decir, el mecenazgo empresarial, en forma directa o a través de una fundación.

De ahí, que el autor, en párrafos siguientes, concluya por afirmar que:

..., si bien es cierto que hasta la fecha cuando se hablaba de política cultural se hada siempre en relación con el papel y las competencias de las instituciones públicas Estado, comunidades autónomas, diputaciones y municipios-, es evidente que cada vez debe tenerse más en consideración, fundamentalmente a causa del papel motor del mecenazgo, el papel de la iniciativa privada, primordialmente de las empresas.

En consecuencia, el papel de la empresa, como organismo vivo inmerso en la sociedad, es crucial; sus objetivos no sólo deben estar dirigidos exclusivamente al logro de un beneficio económico sino también a la consecución de su cuota de responsabilidad con la comunidad en la que se desarrolla.

En relación con lo afirmado en el párrafo anterior, Zappala nos dirá que la promoción privada en las actividades culturales y artísticas no se agota en el sostén financiero, total o parcial, por parte de la empresa, sino que constituye un verdadero y propio servicio a la comunidad, que a su vez sirve para implicar a la empresa en el tejido social en el que opera.

A pesar de que, como se ha afirmado, el beneficio económico es el mejor indicador de que la empresa contribuye al bienestar de toda sociedad, no es menos cierto que la responsabilidad social, como factor constitutivo "per se" del propio fenómeno empresarial, es un concepto más amplio que trasciende el enfoque económico "stricto sensu".

Pues, como muy bien advierte Rhenman,

si la empresa privada desea sobrevivir en una economía libre sin serios inconvenientes, tiene que estar preparada para tomar parte activa en la planificación regional, promover la democracia en las relaciones, trabajar por una mejora del medio ambiente y promocionar otros objetivos políticos.

Nosotros añadiríamos, además, los culturales.

De acuerdo con ello, consideramos que esa participación social activa de la empresa, significa superar los criterios vinculados al mercado para orientarlos a otros fines; esto es, ser un instrumento al servicio del progreso humano, cumpliendo también la función

de promover la cultura. 
A este respecto el empresario Enrique Meijer no duda en afirmar que:

En una sociedad democrática y pluralista debe tenerse en cuenta el pluriformismo del mundo cultural y no pretender, ni interpretar, que las relaciones mutuas de la empresa con su entorno se ciñen a manifestaciones puramente económicas.

No obstante lo afirmado, consideramos, por otro lado, que si la cultura se deja sólo en manos del Estado, se corre el grave riesgo (la historia lo ha demostrado) de caer en la burocratización y en los vicios del poder político y, como consecuencia, la consiguiente politización y dirigismo cultural que, en no pocas ocasiones, suele derivar en propaganda a favor de aquéllos que en ese momento ostentan el poder político.

Sucede asimismo que el intervencionismo absolutista del Estado significaría, como señalara el desaparecido Presidente del Comité Olímpico Español (C.O.E.), Carlos Ferrer Salat:

un empobrecimiento de las posibilidades de la sociedad y también, sin duda, una merma de la libertad. En este aspecto, todas las ideologías democráticas rechazan la dictadura cultural desde el Estado.

Por consiguiente, con independencia de posiciones ideológicas discordantes, la cultura es competencia de todos (no una exclusividad del Estado) y la sociedad civil por medio de los entes colectivos (la empresa fundamentalmente) deben participar en el progreso y fomento de la misma a través de las acciones y de los mecanismo económicos necesarios en los que el patrocinio y el mecenazgo (o patrocinio cultural) constituyen los instrumentos esenciales para lograrlo.

Alineado con nuestras proposiciones, el profesor Vidal Portabales en su análisis de la intervención pública y privada a través del patrocinio y el mecenazgo, nos dirá que:

En definitiva, aunque se pueda teorizar sobre la conveniencia o no de la intervención pública en sectores como el de las artes, el dato decisivo es que hoy, en la generalidad de los países, se tiende a sistemas mixtos, prestando el patrocinio sus estructuras para la consecución de fines que antes asumía el Estado exclusivamente.

De modo análogo, la resolución de los Ministros de Cultura de la U.E., reunidos en el seno del Consejo de 13 de Noviembre de 1986 relativa al patrocinio empresarial de actividades culturales, en su apartado 1 se establecía que:

Los Ministros de Cultura, reunidos en el seno del Consejo, reconocen que la herencia cultural y las actividades culturales europeas en general gozan de una combinación de apoyos públicos y privados. A su juicio, la mejor manera de mantener y desarrollar dicho patrocinio es intensificando los apoyos de variada procedencia, incluyendo diferentes formas de mecenazgo tanto público como privado. 
Precisamente será en este marco donde las acciones de patrocinio y mecenazgo (o patrocinio cultural) adquieren un protagonismo esencial y, la empresa moderna, a través de las mismas, canaliza sus relaciones sociales.

Por ello, tanto el patrocinio como el mecenazgo (como nuevas formas de comunicación empresarial) deben ser concebidos como instrumentos no sólo subordinados a unos objetivos estrictamente económicos o comerciales sino también al servicio de unos fines culturales. Porque ambas estrategias comunicativas y en especial el mecenazgo, al que se refiere Hoog, constituye

...un instrumento precioso de comunicación y un medio de promoción cultural, en una palabra, un instrumento de integración de la empresa en la sociedad.

Como ya reseñábamos al principio, la empresa moderna paulatinamente ha ido adquiriendo más conciencia de su papel social. Este nuevo comportamiento, considerado como una nueva filosofía (algunos la denominan interés propio ilustrado), se está convirtiendo en una nueva forma de concebir la empresa cuyo protagonismo en la vida social es incuestionable.

El criterio general de que todo lo que fuera de interés público era función del Estado, va dejando paso a la idea de integración de la empresa en una esfera de responsabilidades que se extiende más allá de la consecución de metas exclusivamente económicas.

A este respecto Corsolini, citado por el profesor Vidal Portabales, afirma que: Las empresas se han ido empapando de un nuevo rol social que se traduce en una imagen nueva, claramente diferenciada del perfil clásico vinculada a la profesionalidad y a la

economía.

Por tanto, la empresa actual legítimamente se implica con la sociedad en la que está inserta y adquiere una nueva dimensión, para, de esta manera, como recomendara Sol Linowitz (ex-Presidente del Consejo de Administración de la Xeros Corporation),

...hacer de las metas sociales el centro de sus decisiones en cuanto a metas económicas.

Ya no basta con las posiciones neoliberales que, como hemos afirmado, sostenían que:

...el beneficio económico es el mejor indicador de que la empresa contribuye al bienestar de toda sociedad

Las nuevas concepciones reconocen que la empresa debe asumir su responsabilidad con la sociedad y ello significa que la empresa, como consecuencia del lógico y constante proceso evolutivo de nuestra norma de cultura, se concibe de una manera más matizada, es decir, se considera no sólo como una generadora de plusvalías sino también como un instrumento al servicio del progreso humano. 
En esta nueva concepción o filosofía de la empresa actual y su relación con la sociedad, el empleo de las técnicas de patrocinio y mecenazgo cumplen, no sólo y de forma paralela, con la función de ser instrumentos de comunicación para lograr unos objetivos concretos, sino también, como nos recordara Medina, con la misión de actuar

... como una forma de diálogo empresa-sociedad, una especie de impuesto social.

En consecuencia, concluiremos nuestro aserto haciéndolo coincidir con la reflexión realizada por Meenaghan cuando se refiere al patrocinio, esto es:

... una inversión a través de la cual se produce una mezcla de espíritu de donación y de cálculo.

Añadiendo:

En este esquema cabe que la empresa -que dispone de una innegable capacidad de iniciativa- reconcilie este espíritu de cálculo con el de benefactor, convirtiendo estas colaboraciones en beneficiosas para ambas partes, empresa y sociedad. 